\title{
Prevalence and risk factors of autism spectrum disorders in preschool children in Sharkia, Egypt: a community-based study
}

\author{
Amira Mohamed Yousef ${ }^{* *}$ (D), Eman H. Roshdy ${ }^{1}$, Nelly R. Abdel Fattah ${ }^{1}$, Randa M. Said ${ }^{2}$, Maha M. Atia², \\ Elham M. Hafez ${ }^{3}$ and Amany Elshabrawy Mohamed ${ }^{1}$
}

\begin{abstract}
Background: Lateness in the diagnosis of autism spectrum disorders (ASD) results in significant disability and pressure on affected children and their families. We aimed to detect the preschool children who have high-risk criteria for ASD in Sharkia Governorate in Egypt and assess the prevalence and risk factors of ASD. A cross-sectional community-based study was done in 39 kindergartens throughout Sharkia Governorate, Egypt, using a multi-stage random sampling technique. The study included two phases, the screening phase, where 3722 preschool children were screened by Modified Check List for Toddlers/Revised (M-CHAT-R), and the diagnostic phase where the diagnosis of ASD among the high-risk children was made according to the research diagnostic criteria of Diagnostic and Statistical Manual of Mental Disorders 5th edition (DSM-5) of ASD administrated by experienced psychiatrists and the Childhood Autism Rating Scale (CARS).
\end{abstract}

Results: This study showed that $2.8 \%$ of children were at high risk for ASD. The prevalence of ASD in Sharkia Governorate was 5.4/1000. The significant risk factors for the disorder were the presence of factories near the house, first and middle child order, congenital anomalies, child medication during the first year of life, child chronic medical condition, child attachment to TV, a medical condition affecting mother during pregnancy, and psychiatric disorders history in the family.

Conclusion: Autism spectrum disorder is prevalent in preschool children in Sharkia, Egypt, and multiple risk factors contribute to this prevalence.

Keywords: Prevalence, Autism spectrum disorders, Preschool children

\section{Background}

According to "Diagnostic and Statistical Manual of Mental Disorders 5th edition (DSM-5)," autism spectrum disorders (ASD) are neurodevelopmental disorders described by deficits in social communication and social interaction and the presence of restricted, repetitive behaviors [1].

ASD represents a complex lifelong developmental incapability that usually appears during the initial years of

\footnotetext{
*Correspondence: amira76@doctor.com

'Department of Psychiatry, Faculty of Medicine, Zagazig University, Zagazig, Egypt

Full list of author information is available at the end of the article
}

life, even though the diagnosis is not habitually made until later in a child's life, especially when it is mild and perhaps moderate in severity [2].

Children with ASD cannot live independently. Parents of ASD children said that their kids could not live independently without support. Less than $10 \%$ can do the most basic tasks: shopping, cooking, washing clothes, paying bills, and managing money without having help. Also, ASD cases had trouble making companions. ASD also influences numerous parts of family life, not just prompting physical and psychological impairment of parents, additionally creating significant unemployment and monetary problems [3]. 
Early detection of ASD is critical as early intervention leads to significant improvement in intellectual capability and behavioral performance of an increasing proportion of children with ASD. When children are diagnosed in school-age or teens where the brain is more developed, the intervention becomes more challenging along with much less usefulness [4].

Risk factors of ASD are not clearly identified till now. Genetic risk factors are the most significant, and it seems that it is not a single gene. Instead, various genes are included [5]. Some prenatal and perinatal problems were considered as possible risk factors for ASD [6].

Therefore, the current study aimed to identify the preschool children at high risk for ASD in Sharkia Governorate in Egypt and assess the prevalence and risk factors of ASD. That will help in subsequent early diagnosis and intervention.

\section{Method}

\section{Study design and setting}

A community-based cross-sectional study was conducted from the first of March 2017 to the end of January 2018, in 39 kindergartens throughout Sharkia Governorate, Egypt, using a multi-stage random sampling technique as follow:

- 1st stage: We selected five out of 17 districts throughout Sharkia Governorate randomly, which were Zagazig, Minia-Alkamh, Hehia, Kenayat, and Abo-Hamad districts.

- 2nd stage: We selected 39 kindergartens divided into 19 from urban areas and 20 from rural areas randomly from the previously selected communities.

- 3rd stage: All the preschool children in each kindergarten chosen were involved in the study as a cluster sample.

\section{Study subjects}

The sample size was calculated by computer software Epi-info version 6 according to the following: the estimated prevalence of ASD was $2.24 \%$ according to CDC [7], and the total number of preschool children in Sharkia governorate is 595,422 [8], the power of the test is $80 \%$ at $95 \%$ confidence interval (CI). The estimated sample size was 3722 subjects.
a) Inclusion criteria According to the M-CHAT-R, only the children who were classified as high risk for ASD were in- cluded in the diagnostic phase.
b) Exclusion criteria

Children who had an intellectual disability were excluded clinically by the researchers during the diagnostic phase.

\section{Data collection tools \\ Modified Checklist for Autism in Toddlers, Revised (M-CHAT- R) [9]: Arabic version [10]}

The parents filled this screening tool to examine the risk for ASD. It is composed of 20 (yes or no) questions, which are scored as follows: The "NO" response implies ASD risk, with respect to all the items other than 2, 5, and 12; the "YES" answer shows for items 2, 5, and 12 ASD risk.

The following algorithm maximizes the psychometric properties of the M-CHAT-R:

- Low risk: Cumulative score is 0-2; if the infant is less than 24 months, test again after the second birthday. No further intervention is taken until monitoring suggests the risk of ASD.

- Medium risk: Overall score is 3-7; prescribe the follow-up to the risk response system (second level of the M-CHAT-R/F). The child screened positive if the M-CHAT-R/F score stays at two or more. Action needed: transfer the child to the early intervention for diagnostic assessment and eligibility tests. The kid has tested negatively if the follow-up result is $0-1$. Almost no action is appropriate until testing reveals ASD risk. At potential infant appointments, the child should be screened.

- High risk: Overall score is 8-20; the follow-up is appropriate to be circumvented and automatically refer to early detection diagnostic assessing and eligibility determination. Children evaluated by the researchers and the diagnosis of ASD was done according to research diagnosis criteria of DSM-5 of ASD and CARS in that division during the diagnostic phase.

\section{Clinical interview for the diagnosis of ASD}

The diagnosis of ASD was made according to research diagnostic criteria of DSM-5 of ASD that were administrated by experienced psychiatrists (two professors and two assistant professors of the psychiatric department of the University Hospital) using DSM-5 criteria for ASD.

In May 2013, the DSM-5 replaced the previous manual (DSM-IV). The DSM-5 made some significant changes to the way autism is diagnosed. There is now a single diagnosis of autism spectrum disorder, which replaces the formerly used subcategories of autistic disorder, Asperger's disorder, and pervasive developmental disorder not otherwise specified (PDD-NOS) [11]. 


\section{The Childhood Autism Rating Scale (CARS) questionnaire}

This tool helps screen youngsters with ASD and determines symptom severity via quantifiable ratings depending on direct observation. It consists of 15 domains evaluating autism-related behaviors and the overall experiences of autism. Each domain is graded on a scale ranging from one to four; higher scores are correlated with higher disability levels. The child may also be given scores of 1.5, 2.5, or 3.5 if his/her behavior is indicated to be between two descriptions. According to the total score, the child is diagnosed as non-autistic: scores 1529 ; mildly moderately autistic: scores $30-36$; and severely autistic: scores 37-60 [12].

\section{The risk factor assessment questionnaire}

A semi-structured questionnaire was adapted from Moussa et al. [13] and modified by the researcher, then tested by a pilot study. This questionnaire was used to obtain information about the following:

- Demographic data: This domain consisted of 16 items; all were close-ended questions except two open-ended ones.

- Child's perinatal history: This domain was composed of 36 items divided into 28 close-ended questions and eight open-ended ones.

- Developmental history: This domain asked about five areas of child development which were motor (three items), language (two items), cognitive (one item), social, and psychological development (three items).

- Family history: (two close-ended, yes or no questions).

The reliability of the risk factor assessment questionnaire was tested by measuring their internal consistency. It demonstrated an excellent level of reliability (Cronbach's alpha $=0.80$ ).

\section{Operational design \\ Pilot study}

It was carried out in February 2017 on parents of 10 preschool children from a kindergarten in Zagazig City to test the risk factor assessment questionnaire regarding clarity, understanding, consistency, and the time needed to fill it out. Those children were excluded from the main study sample. The pilot study findings showed that the questions were clear and relevant then the questionnaire was ready for use.

\section{Fieldwork}

It was carried out from the first of March 2017 to the end of January 2018. It passed through two phases:
1) Screening phase: Using M-CHAT-R, which took 6 months where the following was done:

- After obtaining official permissions, the researchers interviewed the teachers of the selected kindergartens explaining the purpose of the study and asked them to help distribute the checklists among the parents.

- The checklists were given to the parents by the teachers at the end of the school day when they took their children back home. After telling them about the purpose of the study, they were asked to fill in the checklists, return them on the next day, and be informed about the results.

- The researchers interviewed the parents who refused to fill in the checklists or returned them blank or invalid. They discussed the purpose and importance of this study and offered assistance in filling in the checklist. This was a trial to decrease the nonresponse and the number of invalid checklists.

- The collected checklists were scored by the researchers and classified into low, medium, and high risk.

2) Diagnostic phase: This took 3 months. The researchers interviewed the high-risk group of studied subjects; children evaluated by the researchers and the diagnosis of ASD was done according to research diagnosis criteria of DSM- 5 of ASD and CARS at the psychiatry outpatient clinic in Zagazig University Hospital. The risk factors assessment questionnaires were filled for each of the participants.

\section{Statistical analysis}

Collected data were recorded then analyzed statistically by SPSS version 25. Data were summarized as mean \pm standard deviation for quantitative variables, number, and percentage for qualitative variables. The appropriate statistical tests such as Chi-square, Fisher exact, and student $\mathrm{t}$ tests were used. Binary logistic regression analysis for the significant risk factors for ASD among the studied group was done [14].

\section{Results}

The current study is a cross-sectional study that included 3722 preschool children, with 1973 (53\%) of the studied group were from 2 to 3 years, and 1749 (47\%) were from 4 to 5 years. Regarding sex distribution, 1887 
(50.7\%) were males, and 1835 (49.3\%) were females. By using Modified Checklist for Autism in Toddlers, Revised (M-CHAT-R), 2691 (72.3\%) of the studied group were of low risk for ASD, 927 (24.9\%) were of medium risk, and 104 (2.8\%) were at high risk for ASD (Table 1).

The researcher included four experienced psychiatrists who assessed one hundred four participants (2.8\%) who were high risk for ASD using the research diagnostic criteria of DSM-5 and CARS questionnaire, which showed that 20 children (19.2\%) diagnosed with ASD and 84 (80.8\%) were non-autistic. CARS score among the highrisk group ranged from 16 to 43 (mean 22.73). About 13 children (65\%) had mild to moderate autism, and seven children (35\%) had severe autism.

So, the prevalence of ASD was estimated to be 5.4 per 1000 children (20 children from 3702) (Fig. 1).

Table 2 shows that there was a statistically significant difference between autistic and non-autistic children in age group 4-5 years, mother education (university), presence of factories near the house, and child order. Also, it shows that $15(75 \%)$ of the autistic children mainly were males.

Table 3 shows a statistically significant difference between autistic and non-autistic children in the type of feeding, type of milk, the onset of weaning, and consuming artificial food with $8(40 \%)$ of the autistic children were artificially fed, $8(53.3 \%)$ of the autistic children who were on artificial or combined feeding received powdered milk, 19 (95\%) of all autistic children started to be weaned before 6 months, and $12(60 \%)$ of them consumed artificial food.

As shown in Table 4, there was a statistically significant difference between autistic and non-autistic children in congenital anomaly, medical condition, GIT troubles, and taking medication with all non-autistic children had no congenital anomalies, GIT troubles, or

Table 1 Demographic and clinical characteristics of the studied group

\begin{tabular}{lll}
\hline Variable & $\begin{array}{l}\text { Cases } \\
(\mathbf{n}=\mathbf{3 7 2 2})\end{array}$ & $\%$ \\
\cline { 2 - 3 } & No. & \\
\hline $\begin{array}{lll}\text { Age group } \\
\text { 2-3 years }\end{array}$ & 1973 & 53 \\
4-5 years & 1749 & 47 \\
Sex & & \\
Male & 1887 & 50.7 \\
Female & 1835 & 49.3 \\
Risk & & \\
Low risk & 2691 & 72.3 \\
Medium risk & 927 & 24.9 \\
High risk & 104 & 2.8 \\
\hline
\end{tabular}

history of taking medication versus [15\% (3children), $25 \%$ (5 children), and 10\% ( 2 children)] in the autistic group respectively.

The results showed a statistically significant difference between autistic and non-autistic children in duration of watching TV, and attachment to TV with autistic group had a mean duration of watching TV $6.75 \pm 2.83 \mathrm{~h}$ and $12(60 \%)$ of them had a strong association with TV (Table 5).

Table 6 shows a statistically significant difference between autistic and non-autistic cases in language, early cognitive, and social development.

Table 7 illustrated a statistically significant difference between autistic and non-autistic children in consuming preserved food during pregnancy, a medical condition during pregnancy, and psychiatric disorder history in the family.

As shown in Table 8, the significant risk factors for ASD among the studied group were factories near the house. First and middle child order, congenital anomalies, child medication during the first year of life, chronic medical condition of the child, child attachment to TV, medical condition affecting mother during pregnancy, and psychiatric disorder history in the family.

\section{Discussion}

ASD is a complex lifelong developmental incapability that causes a burden to affected kids and their families. Early detection and early intervention of this problem lead to a better prognosis with fewer burdens on the family. So, our research aimed to detect preschool children in Sharika Governorate who have a high risk for ASD to assess prevalence and risk factors of ASD among them.

In this study, the sex distribution of the studied subjects in the screening phase was $50.7 \%$ males and $49.3 \%$ females. That is similar to the sex distribution in a cross-sectional study performed in Lebanon to assess the prevalence of ASD in kindergartens toddlers in Beirut and Mount-Lebanon [15].

Our results showed that $2.8 \%$ of children assessed using M-CHAT-R during the screening phase were at high risk for ASD, which is in line with the crosssectional descriptive study of Moussa $\mathrm{S}$ and his colleagues, who found that $2 \%$ of children showed an increased risk for ASD [13].

However, this was different from a study that was conducted in India to screen children aged 16-30 months for ASD using M-CHAT-R, and to find an association between maternal, birth, and postnatal risk factors of ASD, and found that $9.4 \%$ of children were at high risk for ASD [16]. This difference could be explained by the difference in the locality and age group of research participants. 


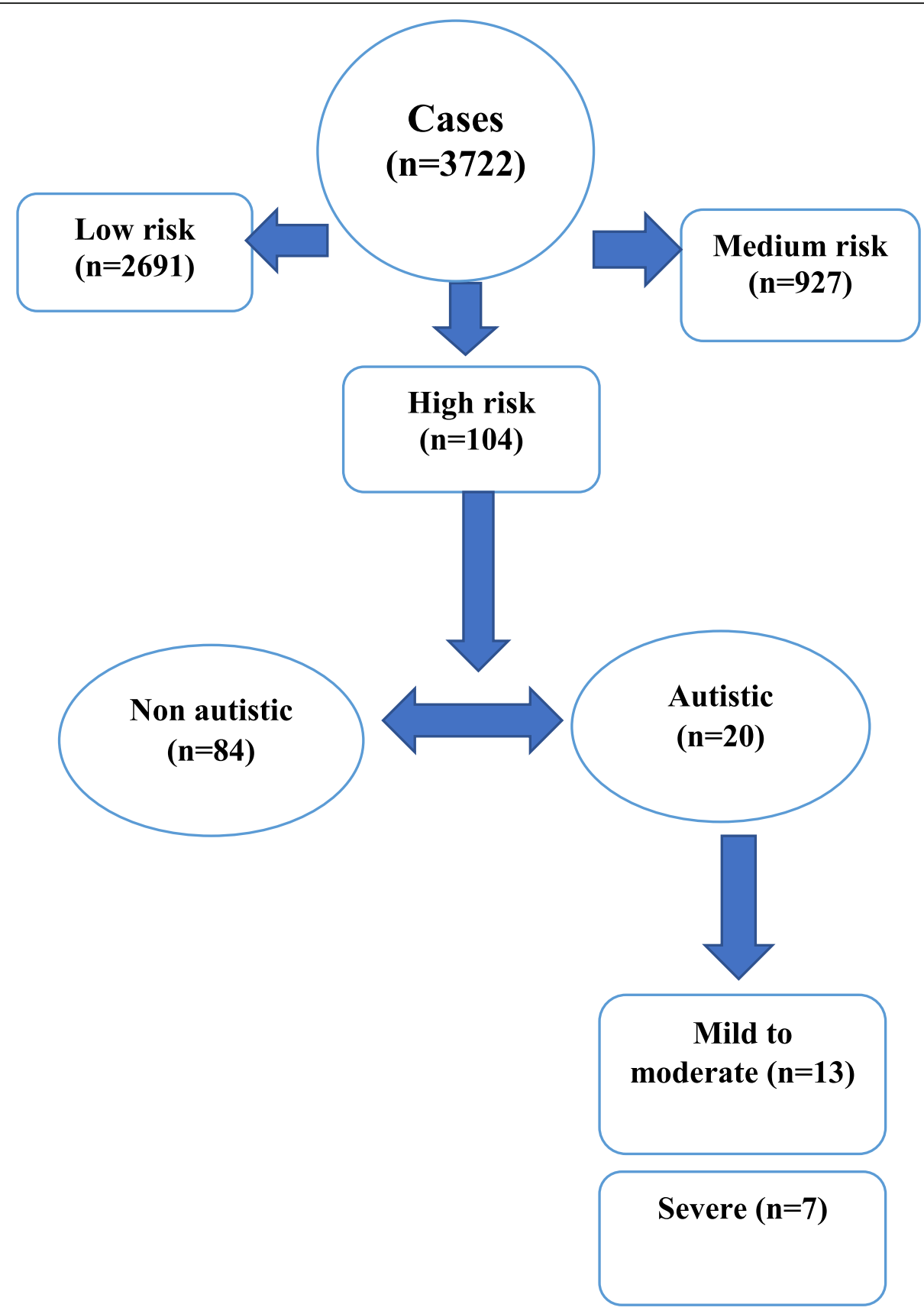

Fig. 1 Flow chart illustrating the distribution of cases from the start till the end of the study

In our study, the mean score on CARS used in the diagnostic phase was $22.73(\mathrm{SD}=6.99)$ with a range of 16-43. That was not consistent with the study of Reszka $\mathrm{S}$ and colleagues, which performed in the USA and showed that the CARS mean score was 33.37 (SD = 7.31) with a range of 15-55.5. This difference may be attributed to the difference in purpose and sampling technique. In our study, CARS was used for diagnosis of ASD among the high-risk children, with more than $80 \%$ of them were non-autistic (score $<30$ ), while in the
American study, most of the children were autistic (score > 30) [17].

Our study showed that $65 \%$ of autistic children were mild to moderate ASD, and 35\% were severe ASD. That was comparable in Saudi Arabia, where $66.7 \%$ of autistic children had mild to moderate ASD, and $33.3 \%$ had severe ASD [18].

An Egyptian study found that $43 \%$ of cases had mild to moderate degree of ASD, and $57 \%$ of them had a severe degree of ASD [19], also different from our study, a 
Table 2 Comparison between autistic and non-autistic children in demographic data

\begin{tabular}{|c|c|c|c|c|c|c|}
\hline \multirow[t]{2}{*}{ Variable } & \multicolumn{2}{|c|}{$\begin{array}{l}\text { Autistic } \\
(\mathrm{n}=20)\end{array}$} & \multicolumn{2}{|c|}{$\begin{array}{l}\text { Non autistic\# } \\
(n=84)\end{array}$} & \multirow[t]{2}{*}{$x^{2}$} & \multirow[t]{2}{*}{$P$} \\
\hline & No. & $\%$ & No. & $\%$ & & \\
\hline \multicolumn{7}{|l|}{ Age group } \\
\hline 4-5 years & 16 & 80 & 39 & 46.4 & Fisher & $0.006^{* *}$ \\
\hline Sex (Male) & 15 & 75 & 53 & 63.1 & 1.01 & 0.32 (NS) \\
\hline \multicolumn{7}{|l|}{ Father education } \\
\hline Read and write & 0 & 0 & 2 & 2.4 & & \\
\hline Middle education & 6 & 30 & 44 & 52.4 & Fisher & 0.13 \\
\hline University & 14 & 70 & 38 & 45.2 & & NS \\
\hline \multicolumn{7}{|l|}{ Mother education } \\
\hline Read and write & 0 & 0 & 2 & 2.4 & & \\
\hline Middle education & 2 & 10 & 41 & 48.8 & Fisher & $0.005^{* *}$ \\
\hline University & 18 & 90 & 41 & 48.8 & & \\
\hline \multicolumn{7}{|l|}{ Father occupation } \\
\hline Employee & 7 & 35 & 33 & 39.3 & & \\
\hline Private work & 13 & 65 & 32 & 38.1 & Fisher & 0.06 \\
\hline Vocational worker & 0 & 0 & 15 & 17.9 & & NS \\
\hline Professional & 0 & 0 & 4 & 4.8 & & \\
\hline \multicolumn{7}{|l|}{ Mother occupation } \\
\hline Housewife & 9 & 45 & 55 & 65.5 & 2.86 & 0.09 \\
\hline Working & 11 & 55 & 29 & 34.5 & & NS \\
\hline \multicolumn{7}{|l|}{ Who care } \\
\hline Father & 5 & 45.4 & 5 & 17.2 & & \\
\hline Grand mom and pap & 3 & 27.3 & 8 & 27.6 & Fisher & 0.25 \\
\hline Kinder garden & 3 & 27.3 & 14 & 48.3 & & NS \\
\hline Other & 0 & 0 & 2 & 6.9 & & \\
\hline \multicolumn{7}{|l|}{ Duration } \\
\hline$<4 h$ & 3 & 27.3 & 2 & 6.9 & Fisher & 0.11 \\
\hline$\geq 4 \mathrm{~h}$ & 8 & 72.7 & 27 & 93.1 & & NS \\
\hline \multicolumn{7}{|l|}{ Social state of parents } \\
\hline Married & 20 & 100 & 82 & 97.6 & Fisher & $\begin{array}{l}0.65 \\
\text { NS }\end{array}$ \\
\hline \multicolumn{7}{|l|}{ Residence } \\
\hline Urban & 13 & 65 & 38 & 45.2 & 2.52 & 0.11 \\
\hline Rural & 7 & 35 & 46 & 54.8 & & NS \\
\hline \multicolumn{7}{|l|}{ Factories near homea } \\
\hline No & 16 & 80 & 84 & 100 & & \\
\hline Yes & 4 & 20 & 0 & 0 & Fisher & $0.001^{* *}$ \\
\hline \multicolumn{7}{|l|}{ Home environment } \\
\hline Extended & 0 & 0 & 2 & 2.4 & Fisher & 0.65 \\
\hline Nuclear & 20 & 100 & 82 & 97.6 & & NS \\
\hline \multicolumn{7}{|l|}{ Smoker inside home } \\
\hline Yes (father) & 9 & 45 & 41 & 48.8 & 0.09 & $\begin{array}{l}0.76 \\
\text { NS }\end{array}$ \\
\hline
\end{tabular}

Sibling number 
Table 2 Comparison between autistic and non-autistic children in demographic data (Continued)

\begin{tabular}{|c|c|c|c|c|c|c|}
\hline \multirow[t]{2}{*}{ Variable } & \multicolumn{2}{|c|}{$\begin{array}{l}\text { Autistic } \\
(\mathrm{n}=20)\end{array}$} & \multicolumn{2}{|c|}{$\begin{array}{l}\text { Non autistic\# } \\
(\mathrm{n}=84)\end{array}$} & \multirow[t]{2}{*}{$x^{2}$} & \multirow[t]{2}{*}{$\mathbf{P}$} \\
\hline & No. & $\%$ & No. & $\%$ & & \\
\hline$\leq 2$ & 10 & 50 & 58 & 69 & 2.59 & 0.11 \\
\hline$<2$ & 10 & 50 & 26 & 31 & & NS \\
\hline \multicolumn{7}{|c|}{ Order of child } \\
\hline First & 10 & 50 & 41 & 48.8 & & \\
\hline Middle & 8 & 40 & 6 & 7.1 & Fisher & $<0.001^{* *}$ \\
\hline Last & 2 & 10 & 37 & 44 & & \\
\hline
\end{tabular}

\#Non-autistic children included here were those of the high-risk group

-Middle education refers to primary, preparatory, secondary, and vocational education

Who care for the child during mother's absence for working

-Any industries that could emit air pollutants and toxins such as sulfur dioxide (SO2), nitric oxides (NOx), and volatile organic compounds (VOC) like

petrochemical industries, iron smelters, oil refineries, polypropylene plants, power companies and methanol industries, formaldehyde plants and urea industries, heavy industries, and metal industries

No answer means that the distance of the child home from the factory is $>20 \mathrm{~km}$

Yes answer means that the distance between the home of the child and the factory is $\leq 20 \mathrm{~km}$

**Statistically significant

study in Rome, Italy, where $44 \%$ of autistic children were with mild to moderate ASD, and $56 \%$ of them were with severe ASD [20]. Those differences were because of the variations in methodology and age groups studied.

In this research, 20 out of 3722 children were diagnosed with ASD using the research diagnostic criteria of DSM-5 and CARS which means Sharkia Governorate ASD prevalence was 5.4/1000 children. The estimated global prevalence was 7.6 per 1000 , according to the systematic review [21].

In the United Arab Emirates, it was 2.9/1000 [22], and in Oman, it was $0.14 / 1000$ [21]. In the UK, the prevalence of ASD was $1.1 \%$ [22], and in the USA, it was $2.24 \%$ [7].

The differences in localities could explain the difference in the prevalence rates of ASD. Diagnosing autism is more common to clinicians in developed countries. Mental health services for autistic children are more available, and families often are more aware of the disorder. These aspects make the diagnosis of ASD more convenient in developed countries than in developing ones. Also, the time difference between this study and the older studies might be responsible for the different prevalence rates. There was an increasing prevalence rate of ASD over the last decade. Additionally, the wide age group interval included in the American study (3-17 years) in comparison to the limited age group interval of this study (2-5 years) was responsible for the prevalence difference from that of American studies.

In our study, most autistic children (80\%) diagnosed by the research diagnostic criteria of DSM-5 and CARS were from 4 to 5 years old, which was in line with Iranian research results [23]. In which ASD patients detected mainly were males (75\%). That was similar to the studies in the USA, which found that $75 \%$ of children having
ASD were males [7] and also with that one which was conducted in Oman to determine ASD prevalence among 0-14 years subjects and found that ASD was more prevalent among boys (75\%) [21]. It was different from the Lebanese study, which found that male: female ratio was 1.05 in Beirut and 1.2 in Mount Lebanon.

This difference might be due to the small sample size of that Lebanese study and the age group difference between the two studies [15]. Ninety percent of mothers of autistic children were university graduates in comparison to $49.4 \%$ of non-autistic children, and this difference was statistically significant. That is consistent with the research undertaken in Saudi Arabia to establish potential risk factors for autism and found a statistically significant disparity between the autistic patients and the control group in mothers' university education [18]. That was also consistent with the study conducted in Assiut City in Egypt to recognize the risk factors for ASD and found that $61.7 \%$ of mothers of autistic children had a university level of education [24].

Our results also showed a statistically significant association between ASD and the presence of factories near the house. We used a proximity method to classify the existence of the child's home from factories with industries that could emit air pollutants and toxins to be near or not. The proximity approach is widely used in many influential environmental epidemiology studies [25-28]. In addition, this method is used frequently in many environmental investigation studies such as in the environmental impact assessment and environmental justice studies [25]. The threshold distance used in the studies assessing the effects of air pollutant industrial complex was up to $20 \mathrm{~km} \mathrm{[25].} \mathrm{To} \mathrm{determine} \mathrm{the} \mathrm{most} \mathrm{appropri-}$ ate definition of the minimum distance for exposure, we reviewed several examples of international housing 
Table 3 Comparison between autistic and non-autistic children in natal and perinatal data

\begin{tabular}{|c|c|c|c|c|c|c|}
\hline \multirow[t]{2}{*}{ Variable } & \multicolumn{2}{|c|}{$\begin{array}{l}\text { Autistic } \\
(\mathrm{n}=20)\end{array}$} & \multicolumn{2}{|c|}{$\begin{array}{l}\text { Non autistic\# } \\
(\mathrm{n}=84)\end{array}$} & \multirow[t]{2}{*}{$x^{2}$} & \multirow[t]{2}{*}{$\mathbf{P}$} \\
\hline & No. & $\%$ & No. & $\%$ & & \\
\hline \multicolumn{7}{|c|}{ Type of pregnancy } \\
\hline Natural & 20 & 100 & 84 & 100 & -- & -- \\
\hline \multicolumn{7}{|l|}{ Gestational age } \\
\hline Full term & 20 & 100 & 84 & 100 & -- & -- \\
\hline \multicolumn{7}{|l|}{ Place of delivery } \\
\hline ZUH & 2 & 10 & 0 & 0 & & \\
\hline Private hospital & 12 & 60 & 78 & 92.9 & Fisher & 0.60 \\
\hline Clinic & 4 & 20 & 4 & 4.8 & & NS \\
\hline Home & 2 & 10 & 2 & 2.4 & & \\
\hline \multicolumn{7}{|l|}{ Mode of delivery } \\
\hline NVD & 12 & 60 & 35 & 41.7 & 2.19 & 0.14 \\
\hline CS & 8 & 40 & 49 & 58.3 & & NS \\
\hline Birth weight & & & & & $\mathrm{t}$ & \\
\hline Mean \pm SD & \multicolumn{2}{|c|}{$3.25 \pm 0.33$} & \multicolumn{2}{|c|}{$3.37 \pm 0.22$} & 1.92 & 0.06 \\
\hline Range & \multicolumn{2}{|c|}{$2.6-3.5$} & \multicolumn{2}{|l|}{$3-3.5$} & & NS \\
\hline
\end{tabular}

\section{Complication at birth}

$\begin{array}{lllllll}\text { No } & 20 & 100 & 78 & 92.9 & \text { Fisher } & 0.41 \\ \text { Yes } & 0 & 0 & 6 & 7.1 & & \text { NS }\end{array}$

\section{Incubator}

$\begin{array}{lllllll}\text { No } & 20 & 100 & 80 & 95.2 & \text { Fisher } & 0.42 \\ \text { Yes } & 0 & 0 & 4 & 4.8 & & \text { NS }\end{array}$

\section{Feeding}

$\begin{array}{lllll}\text { Breast feeding } & 5 & 25 & 50 & 59.5\end{array}$

$\begin{array}{lllll}\text { Artificial } & 8 & 40 & 18 & 21.4\end{array}$

\section{$7.730 .02 *$}

Combined

Type of milk

$\begin{array}{lllll}\text { Fresh animal } & 7 & 46.7 & 0 & 0\end{array}$

Powdered milk $\quad 8 \quad 53.3 \quad 34 \quad 100$

Onset of weaning

$$
\begin{array}{lllll}
\leq 6 \text { months } & 19 & 95 & 50 & 59.5 \\
\geq 6 \text { months } & 1 & 5 & 34 & 40.5
\end{array}
$$

Fisher $<0.001^{* *}$

\section{Artificial food}

\begin{tabular}{lllllll} 
No & 8 & 40 & 73 & 86.9 & $\mathbf{2 0 . 6 3}$ & $<\mathbf{0 . 0 0 1 * *}$ \\
Yes & 12 & 60 & 11 & 13.1 & & \\
\hline
\end{tabular}

\#Non-autistic children included here were those of the high-risk group **Statistically significant

policies upon that we considered that if the distance of the child home from the factory is $>20 \mathrm{~km}$ so it is not near the home and if the distance is $\leq 20 \mathrm{~km}$, so the home of the child is near the factory. Factories were sources of air pollution leading to perinatal exposure of those children to the hazardous chemicals and fumes

\begin{tabular}{|c|c|c|c|c|c|c|}
\hline \multirow[t]{2}{*}{ Variable } & \multicolumn{2}{|c|}{$\begin{array}{l}\text { Autistic } \\
(n=20)\end{array}$} & \multicolumn{2}{|c|}{$\begin{array}{l}\text { Non autistic\# } \\
(n=84)\end{array}$} & \multirow[t]{2}{*}{$x^{2}$} & \multirow[t]{2}{*}{$\mathbf{P}$} \\
\hline & No. & $\%$ & No. & $\%$ & & \\
\hline \multicolumn{7}{|c|}{ Congenital anomalies } \\
\hline No & 17 & 85 & 84 & 100 & Fisher & $0.006^{* *}$ \\
\hline Yes & 3 & 15 & 0 & 0 & & \\
\hline
\end{tabular}
emitted from those factories. That was consistent with
Table 4 Comparison between autistic and non-autistic children in child medical history

\section{Chronic medical}

$\begin{array}{lllllll}\text { No } & 14 & 70 & 79 & 94 & \mathbf{9 . 8 8} & \mathbf{0 . 0 0 2}^{* *} \\ \text { Yes } & 6 & 30 & 5 & 6 & & \end{array}$

$\begin{array}{lllllll}\text { Neonatal infection } & & & & & & \\ \text { No } & 20 & 100 & 5 & 6 & \text { Fisher } & 0.34 \\ \text { Yes } & 0 & 0 & 79 & 94 & \text { NS }\end{array}$

GIT troubles

$\begin{array}{llllll}\text { No } & 15 & 75 & 84 & 100 & \text { Fisher }<0.001^{* *} \\ \text { Yes } & 5 & 25 & 0 & 0 & \end{array}$

Sleeping troubles

$\begin{array}{lllllll}\text { No } & 20 & 100 & 84 & 100 & -- & - \\ \text { Take medication } & & & & & & \\ \text { No } & 18 & 90 & 84 & 100 & \text { Fisher } & \mathbf{0 . 0 4} \\ \text { Yes } & 2 & 10 & 0 & 0 & & \\ \text { Allergy } & & & & & & \\ \text { No } & 17 & 85 & 81 & 96.4 & \text { Fisher } & 0.06 \\ \text { Yes } & 3 & 15 & 3 & 3.6 & & \text { NS } \\ \text { Hospitalization } & & & & & & \\ \text { No } & 20 & 100 & 82 & 97.6 & \text { Fisher } & 0.65 \\ \text { Yes } & 0 & 0 & 2 & 2.4 & & \text { NS } \\ \text { Operation } & & & & & & \\ \text { No } & 17 & 85 & 80 & 95.2 & \text { Fisher } & 0.08 \\ \text { Yes } & 3 & 15 & 4 & 4.8 & & \text { NS }\end{array}$

Child abuse

$\begin{array}{lllllll}\text { No } & 20 & 100 & 84 & 100 & -- & --\end{array}$ **Statistically significant

the research performed in the USA to examine the theory that perinatal air pollutants exposure is correlated with ASD [29].

In our study, a statistical difference between autistic and non-autistic children in birth orders where $40 \%$ of autistic children were first born while $50 \%$ were of middle birth order. That was inconsistent with the finding of the meta-analysis study of Gardener and his colleagues that aimed at providing the first quantitative review and meta-analysis of the association between maternal pregnancy complications, and pregnancy-related factors, and risk of Autism, and found that being firstborn versus third or later was significantly increased autism risk [5]. That was also inconsistent with the finding of the other 
Table 5 Comparison between autistic and non-autistic children in watching TV

\begin{tabular}{|c|c|c|c|c|c|c|}
\hline \multirow[t]{2}{*}{ Variable } & \multicolumn{2}{|l|}{$\begin{array}{l}\text { Autistic } \\
(n=20)\end{array}$} & \multicolumn{2}{|c|}{$\begin{array}{l}\text { Non autistic\# } \\
(n=84)\end{array}$} & \multirow[t]{2}{*}{$x^{2}$} & \multirow[t]{2}{*}{$\mathbf{P}$} \\
\hline & No. & $\%$ & No. & $\%$ & & \\
\hline \multicolumn{7}{|c|}{ Age of beginning TV (in months) } \\
\hline Mean \pm SD & \multicolumn{2}{|l|}{$18.1 \pm 8.6$} & \multicolumn{2}{|l|}{$18.83 \pm 6.7$} & \multirow{2}{*}{$\begin{array}{l}\text { MW } \\
1.22\end{array}$} & \multirow{2}{*}{$\begin{array}{l}0.22 \\
\text { NS }\end{array}$} \\
\hline Range & \multicolumn{2}{|l|}{$8-36$} & \multicolumn{2}{|l|}{$8-36$} & & \\
\hline \multicolumn{7}{|c|}{ Duration of TV watch } \\
\hline Mean \pm SD & \multicolumn{2}{|l|}{$6.75 \pm 2.83$} & \multicolumn{2}{|l|}{$2.55 \pm 1.64$} & \multirow{2}{*}{$\begin{array}{l}\text { MW } \\
4.82\end{array}$} & \multirow[t]{2}{*}{$<0.001^{* *}$} \\
\hline Range & $1-11$ & & $0.5-9$ & & & \\
\hline \multicolumn{7}{|c|}{ Attachment to TV } \\
\hline Weak & 3 & 15 & 47 & 56 & & \\
\hline Intermediate & 3 & 15 & 33 & 39.3 & & \\
\hline Strong & 12 & 60 & 2 & 2.4 & \multirow[t]{2}{*}{ Fisher } & \multirow[t]{2}{*}{$<0.001^{* *}$} \\
\hline Very strong & 2 & 10 & 2 & 2.4 & & \\
\hline
\end{tabular}

meta-analysis study that aimed at identifying pre-, peri-, and neonatal risk factors for pervasive developmental disorders (PDD), including autism and found that being firstborn was significantly associated with risk ASD [30].

This difference might be due to the difference in locality and population characteristics, as all the studies included in the meta-analysis of both studies were from developed foreign countries. This study showed a statistically significant association between ASD and artificial feeding and early weaning. This was consistent with the Indian study, which showed that delayed initiation of breastfeeding was significantly associated with the risk of ASD. In contrast, exclusive breastfeeding in the first 6 months of life was associated with decreased risk [16]. The systematic review study in Arab Gulf countries findings found that delayed breastfeeding and no colostrum ingestion were linked to a higher risk of autism. Extended breastfeeding (up to 24 months) significantly decreased the likelihood of developing it [31].

In this study, $60 \%$ of autistic children consumed artificial, preserved, and canned food in comparison to $13.1 \%$ of non-autistic, and this difference was statistically significant. That was consistent with a study conducted in Turkey to examine the connection between ASD development and exposure to MEHP, DEHP, and BPA which are used in some food like meat products and canned beef, also in drink packaging, and to coat metal products such as food cans and bottle tops. This Turkish study found that autistic children showed elevated serum MEHP, DEHP, and BPA levels. Significantly, compared to healthy control subjects, they might play a part in autism spectrum disorder pathogenesis [32].
Our results showed a significant increase in congenital anomalies in autistic children compared to non-autistic children. This finding is similar to that of the metaanalysis study that aimed at providing the first review and meta-analysis of the correlation between perinatal and neonatal factors and autism risk and found that congenital deformities have been linked with the risk of ASD [6].

Our results showed that chronic medical conditions (mainly epilepsy) and GIT troubles were significantly correlated with autism in the affected children, consistent with the study in Iran, which showed that ADHD and epileptic disorders were the leading comorbidities [33]. And also, an American study showed that functional constipation was the most prevalent form of GID in autistic children (85.0\%), GID was not correlated with specific feeding habits or medical status in children with ASD, and the likelihood of constipation was associated with younger age, more social impairment, and lack of expressive language [34]..

This study showed a statistically significant difference between autistic and non-autistic children in the duration of watching TV and attachment to TV. The mean time spent in TV watching by the ASD cases was more than $6 \mathrm{~h}$ per day, and $60 \%$ of those autistic children were firmly attached to a TV compared to only $2.4 \%$ of nonautistic. These findings were consistent with the study conducted in Bangladesh to clarify the association between risk and autism for families, communities, and the environment. They found that the diagnosis of autism is closely connected to excessive watching of TV and the insufficient ability to social interaction and poor contact with family members in early childhood [35]. 
Table 6 Comparison between autistic and non-autistic children in immunization and developmental history

\begin{tabular}{|c|c|c|c|c|c|c|}
\hline \multirow[t]{2}{*}{ Variable } & \multicolumn{2}{|c|}{$\begin{array}{l}\text { Autistic } \\
(\mathrm{n}=20)\end{array}$} & \multicolumn{2}{|c|}{$\begin{array}{l}\text { Non autistic\# } \\
(n=84)\end{array}$} & \multirow[t]{2}{*}{$x^{2}$} & \multirow[t]{2}{*}{$\mathbf{P}$} \\
\hline & No. & $\%$ & No. & $\%$ & & \\
\hline \multicolumn{7}{|c|}{ Hypothyroidism screening } \\
\hline Yes & 20 & 100 & 84 & 100 & -- & -- \\
\hline \multicolumn{7}{|l|}{ Immunization } \\
\hline Complete & 20 & 100 & 84 & 100 & -- & -- \\
\hline \multicolumn{7}{|c|}{ Motor development } \\
\hline \multicolumn{7}{|l|}{ Head support } \\
\hline Normal & 18 & 90 & 78 & 92.9 & Fisher & 0.84 \\
\hline Delayed & 2 & 10 & 6 & 7.1 & & NS \\
\hline \multicolumn{7}{|c|}{ Sitting without support } \\
\hline Normal & 20 & 100 & 80 & 95.2 & Fisher & 0.92 \\
\hline Delayed & 0 & 0 & 4 & 4.8 & & NS \\
\hline \multicolumn{7}{|c|}{ Walking without support } \\
\hline Normal & 19 & 95 & 81 & 96.4 & Fisher & 0.87 \\
\hline Delayed & 1 & 5 & 3 & 3.6 & & NS \\
\hline \multicolumn{7}{|l|}{ Language } \\
\hline \multicolumn{7}{|l|}{ Babbling } \\
\hline Normal & 7 & 35 & 84 & 100 & Fisher & $<0.001^{* *}$ \\
\hline Delayed & 13 & 65 & 0 & 0 & & \\
\hline \multicolumn{7}{|c|}{ Dada and mama } \\
\hline Normal & 7 & 35 & 78 & 92.9 & Fisher & $<0.001^{* *}$ \\
\hline Delayed & 13 & 65 & 6 & 7.1 & & \\
\hline \multicolumn{7}{|c|}{ Early cognitive } \\
\hline \multicolumn{7}{|c|}{ Hidden object } \\
\hline Normal & 7 & 35 & 82 & 97.6 & Fisher & $<0.001^{* *}$ \\
\hline Delayed & 13 & 65 & 2 & 2.4 & & \\
\hline \multicolumn{7}{|c|}{ Social and psychological } \\
\hline \multicolumn{7}{|c|}{ Social smile } \\
\hline Normal & 10 & 50 & 84 & 100 & Fisher & $<0.001^{* *}$ \\
\hline Delayed & 10 & 50 & 0 & 0 & & \\
\hline \multicolumn{7}{|c|}{ Recognize mother } \\
\hline Normal & 17 & 85 & 84 & 100 & Fisher & $<0.001^{* *}$ \\
\hline Delayed & 3 & 15 & 0 & 0 & & \\
\hline \multicolumn{7}{|c|}{ Assist in dress } \\
\hline Normal & 14 & 70 & 84 & 100 & Fisher & $<0.001^{* *}$ \\
\hline Delayed & 6 & 30 & 0 & 0 & & \\
\hline
\end{tabular}

\#Non-autistic children included here were those of the high-risk group

**Statistically significant

Also, in agreement with these findings, the study conducted in Thailand to analyze the level and degree of television consumption in children with ASD relative to typically developed subjects identified a greater incidence of television viewing in autistic children than children with typical development. And that there was an early initiation of TV exposure in autistic children compared to children with typical developments [36].

We found a statistically significant delay in language, early cognitive, social, and psychological development among children with ASD in our study. On the other hand, there was no statistically significant delay in motor 
Table 7 Comparison between autistic and non-autistic children in parents and family history

\begin{tabular}{|c|c|c|c|c|c|c|}
\hline \multirow{2}{*}{$\begin{array}{l}\text { Variable } \\
\text { Father age at ges. }\end{array}$} & \multicolumn{2}{|c|}{$\begin{array}{l}\text { Autistic } \\
(n=20)\end{array}$} & \multicolumn{2}{|c|}{$\begin{array}{l}\text { Non autistic\# } \\
(n=84)\end{array}$} & \multirow[t]{2}{*}{$\mathbf{t}$} & \multirow[t]{2}{*}{$\mathbf{P}$} \\
\hline & & & & & & \\
\hline Mean \pm SD & \multicolumn{2}{|c|}{$31.9 \pm 4.58$} & \multicolumn{2}{|c|}{$30.27 \pm 4.68$} & 1.40 & \multirow{2}{*}{$\begin{array}{l}0.16 \\
\text { NS }\end{array}$} \\
\hline Range & \multicolumn{2}{|c|}{$25-40$} & \multicolumn{2}{|c|}{$23-43$} & & \\
\hline \multicolumn{7}{|l|}{ Mother age at ges. } \\
\hline Mean \pm SD & \multicolumn{2}{|c|}{$26.75 \pm 4$} & \multicolumn{2}{|c|}{$26.36 \pm 4.21$} & 0.38 & \multirow{2}{*}{$\begin{array}{l}0.71 \\
\text { NS }\end{array}$} \\
\hline Range & \multicolumn{2}{|c|}{$22-34$} & \multicolumn{2}{|c|}{$19-39$} & & \\
\hline Variable & No. & $\%$ & No. & $\%$ & $x^{2}$ & $\mathbf{P}$ \\
\hline \multicolumn{7}{|c|}{ Drug intake during Pregnancy } \\
\hline No & 20 & 100 & 84 & 100 & -- & -- \\
\hline \multicolumn{7}{|c|}{ Progesterone during pregnancy } \\
\hline No & 17 & 85 & 80 & 95.2 & Fisher & 0.10 \\
\hline Yes & 3 & 15 & 4 & 4.8 & & NS \\
\hline \multicolumn{7}{|l|}{ Alcohol during pregnancy } \\
\hline No & 20 & 100 & 84 & 100 & -- & -- \\
\hline \multicolumn{7}{|l|}{ Smoking during pregnancy } \\
\hline No & 20 & 100 & 84 & 100 & -- & --- \\
\hline \multicolumn{7}{|c|}{ Preserved food during pregnancy } \\
\hline No & 7 & 35 & 53 & 63.1 & 5.22 & $0.02^{*}$ \\
\hline Yes & 13 & 65 & 31 & 36.9 & & \\
\hline \multicolumn{7}{|c|}{ Complication during pregnancy } \\
\hline No & 20 & 100 & 82 & 97.6 & Fisher & 0.65 \\
\hline Yes & 0 & 0 & 2 & 2.4 & & NS \\
\hline \multicolumn{7}{|c|}{ Medical condition during pregnancy } \\
\hline No & 10 & 50 & 84 & 100 & Fisher & $<0.001^{* *}$ \\
\hline Yes & 10 & 50 & 0 & 0 & & \\
\hline HPT & 7 & 35 & ---- & ---- & & \\
\hline Celiac disease & 3 & 15 & & & & \\
\hline \multicolumn{7}{|l|}{ ASD in family } \\
\hline No & 20 & 100 & 84 & 100 & -- & -- \\
\hline \multicolumn{7}{|c|}{ Psychiatric disorders in the family } \\
\hline No & 18 & 90 & 84 & 100 & Fisher & $0.04^{*}$ \\
\hline Yes & 2 & 10 & 0 & 0 & & \\
\hline
\end{tabular}

\#Non-autistic children included here were those of the high-risk group **Statistically significant

development. That was similar to the Saudi study findings that did not show a significant difference between cases and controls in motor mil-stones (sitting and walking) [18].

Meanwhile, we found a statistically significant difference between autistic children and the control group in delayed language development and mother recognition. That was inconsistent with the Egyptian study; El-Baz F and his colleagues examined the potential risk factors of autism and found that all the developmental milestones analyzed were delayed in the autistic children than the control group [19]. This difference might be because $55 \%$ of autistic patients in that study had an intellectual disability, while those with intellectual disability were excluded from our research.

The Egyptian study of El-Baz F and his colleagues also showed a statistically significant difference for autistic children and controls in the elevated maternal age (mother $=35$ years) at birth, advanced parent age (father = 35 years) at birth, and positive family history of autism [19] that was in contrast to the results of our study which showed no differences. This difference might be 
Table 8 Binary logistic regression analysis for the significant risk factors for ASD among the studied group

\begin{tabular}{|c|c|c|c|c|c|c|c|}
\hline \multirow{2}{*}{$\begin{array}{l}\text { Variable } \\
\text { Age group 4-5 years }\end{array}$} & \multirow{2}{*}{$\begin{array}{l}\text { B } \\
0.42\end{array}$} & \multirow{2}{*}{$\begin{array}{l}\text { S.E. } \\
0.05\end{array}$} & \multirow{2}{*}{$\begin{array}{l}\text { Wald } \\
1.00\end{array}$} & \multirow{2}{*}{$\begin{array}{l}\text { Sig. } \\
0.76\end{array}$} & \multirow{2}{*}{$\begin{array}{l}\text { OR } \\
1.52\end{array}$} & \multicolumn{2}{|c|}{ 95.0\% C.I. } \\
\hline & & & & & & 0.76 & 3.21 \\
\hline University educated mother & 3.09 & 0.13 & 1.93 & 0.08 & 1.99 & 0.82 & 4.65 \\
\hline Factories near house & 74.08 & 0.99 & 13.89 & $<0.001^{* *}$ & 14.90 & 4.72 & 34.76 \\
\hline First and middle child & 32.74 & 0.68 & 8.28 & $<0.001^{* *}$ & 16.28 & 6.73 & 45.87 \\
\hline Not exclusive breast feeding & 0.60 & 0.03 & 2.29 & 0.89 & 1.83 & 0.56 & 3.85 \\
\hline Fresh milk in feeding & 0.46 & 0.06 & 3.07 & 0.93 & 1.59 & 0.45 & 2.99 \\
\hline Artificial food & 2.94 & 0.16 & 1.12 & 0.45 & 1.65 & 0.56 & 3.74 \\
\hline Congenital anomalies & 33.38 & 0.54 & 8.52 & $<0.001^{* *}$ & 31.55 & 19.43 & 65.41 \\
\hline Chronic medical condition & 37.66 & 0.84 & 7.71 & $<0.001^{* *}$ & 22.68 & 12.47 & 42.84 \\
\hline GIT troubles & 3.38 & 0.12 & 1.81 & 0.08 & 1.57 & 0.30 & 6.76 \\
\hline Medication intake & 33.58 & 0.83 & 5.56 & $<0.001^{* *}$ & 30.45 & 18.45 & 59.32 \\
\hline Strong attachment to TV & 36.32 & 0.82 & 8.61 & $<0.001 * *$ & 29.82 & 7.45 & 53.29 \\
\hline$>6 \mathrm{~h}$ watching TV & 2.01 & 0.12 & 1.51 & 0.07 & 1.49 & 0.53 & 4.56 \\
\hline Canned food during pregnancy & 1.47 & 0.09 & 0.14 & 0.12 & 0.95 & 0.23 & 3.45 \\
\hline Medical condition in pregnancy & 6.21 & 0.34 & 2.64 & $0.03 *$ & 10.53 & 3.23 & 26.23 \\
\hline Psychiatric disorder in family & 23.45 & 0.51 & 6.23 & $0.01 *$ & 16.78 & 5.67 & 31.83 \\
\hline
\end{tabular}

**Statistically significant

due to the methodological difference between the two studies.

Our study showed a statistically significant increase in the maternal consumption of artificial, preserved, and canned food during pregnancy among the mothers of autistic children $(65 \%)$ compared to $(36.9 \%)$ mothers of non-autistic, consistent with the study of De Cock M and his colleagues which was conducted to provide a review of research on perinatal human sensitivity to endocrine disrupting chemicals (EDCs) in relation to ASD and ADHD and identified significant correlations between ASD and the exposure to the examined chemicals, including toxic air contaminants, pesticides, and bisphenol [37].

We found a statistically significant difference between autistic and non-autistic children in the presence of a history of chronic medical condition during pregnancy where $35 \%$ of autistic children had a history of maternal hypertension with pregnancy, and $15 \%$ had a history of maternal celiac disease. This was in line with the findings of the research of Walker $\mathrm{Ch}$ and his colleagues in the USA, which found that preeclampsia was associated with the development of ASD [38], and in Denmark, a study of Atladóttir HO1 and his colleagues found that maternal history of rheumatoid arthritis and celiac disease elevated the like hood of developing autism [39].

In our study, $10 \%$ of autistic children had a family history of psychiatric disorders than $0 \%$ of non-autistic children, which was statistically significant. This is similar to the study of Alsulaimani A and his colleagues in Saudi Arabia [18].
The statistically significant risk factors for ASD among the studied group by using binary logistic regression analysis were the presence of factories near the house, first and middle child order, congenital anomalies, child medication during the first year of life, chronic medical condition of child, child attachment to TV, medical condition affecting mother during pregnancy, and psychiatric disorders history in the family.

The statistically significant risk factors for ASD in that Saudi study were the older age of the fathers, positive family history of the psychiatric disorder including autism, history of maternal diabetes mellitus, and the mother's exposure to stress during pregnancy. Also, Gardener $\mathrm{H}$ and his colleagues in their meta-analysis research revealed that advanced paternal age at birth, maternal prenatal medication usage, gestational diabetes, bleeding, and firstborn were associated with ASD risk were [6].

Our present study had some limitations; first, we included only the children with high risk for ASD in the diagnostic phase due to limited time and resources. Second, the preschool children who go to kindergartens were only included in this study without including household preschoolers. This study did not include those younger than two years of age. Third, The MCHA $\mathrm{T}-\mathrm{R}$ has a high false-positive rate. Fourth, the risk factors assessment questionnaires included items that were very subjective like the attachment to TV. Fifth, the nonresponse rate was increased by about $40 \%$ due to the refusal of many parents to participate in the study, refusal of some school managers to perform the study on their 
children, illiteracy and low educational level of many parents, and neglect of some parents to fill in the checklist. Some parents refused to complete the second diagnostic phase of the study, causing some dropouts among the high-risk group, and we excluded them from the second diagnostic phase's statistical analysis. This might be attributed to the fear of stigma perceived by some parents if their children were diagnosed with ASD and the feeling of some parents that the study was not useful for them.

\section{Conclusion}

Autism spectrum disorder is prevalent in preschool children in Sharkia, Egypt, and multiple risk factors contribute to this prevalence.

\section{Abbreviations}

ASD: Autism spectrum disorders; CARS: Childhood Autism Rating Scale; DSM5: Diagnostic and Statistical Manual of Mental Disorders 5th edition; M-CHATR: Modified Checklist for Autism in Toddlers, Revised; CARS: Childhood Autism Rating Scale; SO2: Sulfur dioxide; NOx: Nitric oxides; VOC: Volatile organic compounds; ADOS: Diagnostic and observation schedule; SRS: Social Responsiveness Scale; UK: United Kingdom; USA: United States of America; PDD: Pervasive developmental disorders; MEHP: mono-(2-Ethylhexyl) phthalate; DEHP: di-(2-Ethylhexyl) phthalate; BPA: Bisphenol A; GIT: Gastrointestinal tract; GID: Gastrointestinal dysfunction; ADHD: Attention deficit hyperactivity disorder; EDCs: Endocrine disrupting chemicals

\section{Acknowledgements}

Not applicable

\section{Authors' contributions}

AMY, NRA, AEM, and EHR designed the work and made the diagnosis of ASD among the high-risk group and applied the psychometric assessment. RMS and MMA shared in designing the study, collection of data, and put the sequence of work phases. EMH helped in collecting the data. All authors contributed to the conception, preparation, and writing of this article. AMY gave the paper a final review and then forwarded the report for publication. The authors read and approved the final manuscript.

\section{Funding}

No fund was received for this work.

\section{Availability of data and materials Upon request}

\section{Declarations}

\section{Ethics approval and consent to participate}

We had an approval from the Ethical Committee of the Faculty of Medicine, Zagazig University, Egypt (IRB\# 2016). The necessary official permissions to carry out the study were obtained from the Educational and Social Solidarity directorates.

We obtained a written informed consent from parents of the children of the high-risk group before filling the questionnaires. They were reassured about the strict confidentiality of any received information, and that the study results would be used only for research. The study procedures were free from any harmful effects on the participants.

\section{Consent for publication}

Not applicable

\section{Competing interests}

The authors declare that they have no competing interests.

\section{Author details}

'Department of Psychiatry, Faculty of Medicine, Zagazig University, Zagazig, Egypt. ${ }^{2}$ Family Medicine Department, Faculty of Medicine, Zagazig University, Zagazig, Egypt. ${ }^{3}$ Otorhinolaryngology Department, Faculty of Medicine,

Zagazig University, Zagazig, Egypt.

Received: 4 May 2021 Accepted: 10 June 2021

Published online: 21 July 2021

\section{References}

1. American Psychiatric Association (2013) Diagnostic and statistical manual of mental disorders, 5th ed. American Psychiatric Publishing, Arlington, VA

2. Seif Eldin A, Habib D, Noufal A, Farrag S, Bazaid K, Al-Sharbati M, Badr H, Moussa S, Essali A, Gaddour N (2008) Use of M-CHAT for a multinational screening of young children with autism in the Arab countries. International Review of Psychiatry 20(3):281289

3. Barnard J, Harvey V, Potter D (2001) Ignored or ineligible? The reality for adults with autism spectrum disorders. National Autistic Society, London

4. Dawson G, Rogers S, Munson J, Smith M, Winter J, Greenson J, Donaldson A, Varley J (2010) Randomized, controlled trial of an intervention for toddlers with autism: the Early Start Denver Model. Pediatric 125(1):e17-e23

5. Freitag CM, Staal W, Klauck SM (2010) Genetics of autistic disorders: review and clinical implications. Eur Child Adolesc Psychiatry 19(3):169-178. https:// doi.org/10.1007/s00787-009-0076-x

6. Gardener H, Spiegelman D, Buka SL (2011) Prenatal risk factors for autism: comprehensive meta-analysis. Br J Psychiatry 195(1):7-14

7. Zablotsky B, Black L, Maenner M (2015) Estimated prevalence of autism and other developmental disabilities following questionnaire changes in the 2014 National Health Interview Survey. Centers for Disease Control and Prevention, National Center for Health Statistics. Natl Health Stat Report 87: $1-20$

8. Egypt-statistical year book 2015 Available at http://www.ara bdevelopmentportal.com/publication/egypt-statistical-yearbook-2015-educa tion

9. Robins D, Casagrande K, Barton M. Validation of the modified checklist for autism in toddlers-revised with follow-up (M-CHAT-R/F). International Society for Autism Research. Available at: https://imfar.confex.com/imfar/2 014/web.program/Paper16689.htmlAccessed at: February 8, 2017. (2014)

10. Modified checklist for autism in toddlers-revised with follow-up (M-CHAT-R/F). Arabic version Translated by: Dr. Mona Fathelbab, Prof. Suaad Moussa, 2014

11. American Psychiatric Association (2013) Diagnostic and statistical manual of mental disorders, 5th edn. American Psychiatric Association, Arlington, VA. https://doi.org/10.1176/appi.books.9780890425596

12. Schopler E, Reichler R, Renner B. The childhood autism rating scale (CARS); 2010. Available at: http://addwarehouse.com/shopsite_sc/store/html/ childhood-autism-rating-scale-cars-forms.html

13. Moussa S, Fawaz L, Mostafa M (2013) Early Screening of autistic spectrum disorder in children attending primary health care units

14. IBM (2017) IBM SPSS Statistics for Windows, Version 25. IBM Corp, Armonk, NY http://www-01.ibm.com/support/docview.wss?uid=swg 27049428

15. Chaaya M, Saab D, Maalouf FT, Boustany RM (2016) Prevalence of autism spectrum disorder in nurseries in Lebanon: a cross-sectional study. J Autism Dev Disord 46(2):514-522. https://doi.org/10.1007/s10803-015-2590-7

16. Ravi S, Chandrasekaran V, Kattimani S (2016) Maternal and birth risk factors for children screening positive for autism spectrum disorders on M-CHAT-R. Asian J Psychiatr 22:17-21

17. Reszka S, Boyd B, McBee M (2014) Brief report: concurrent validity of autism symptom severity measures. J Autism Dev Disord 44(2):466-470. https://doi. org/10.1007/s10803-013-1879-7

18. Alsulaimani A, Helmy F, Abdel Wahab M (2014) Risk factors of autism: a Saudia Study. International Journal of Science and Research 3(10):1200-1210

19. el-Baz F, Ismael N, el-Din SMN (2011) Risk factors for autism: an Egyptian Study. The Egyptian Journal of Medical Human Genetic 12(1):31-38. https:// doi.org/10.1016/j.ejmhg.2011.02.011

20. Rellini E, Tortolani D, Trillo S (2004) Childhood autism rating scale (CARS) and autism behavior $(\mathrm{ABC})$ correspondence and conflicts with DSM-IV criteria in diagnosis of autism. J Autism Dev Disord 34(6):703-708. https:// doi.org/10.1007/s10803-004-5290-2

21. Al-Farsi YM, Al-Sharbati MM, Al-Farsi OA, Al-Shafaee MS, Brooks DR, Waly MI (2010) Brief report: prevalence of autistic spectrum disorders in the sultanate of Oman. J Autism Dev Disord 41(6):821-825 
22. The National Autistic Society: Autism facts and history. 2016 Available at: http://www.autism.org.uk/about/whatis/myths-facts-stats.aspx. Accessed at: the twenty-ninth of December, 2016.

23. Samadi SA, McConkey R (2015) Screening for autism in Iranian preschoolers: contrasting M-CHAT and a scale developed in Iran. J Autism Dev Disord 45(9):2908-2916

24. Elwardany S, Ibrahim H, Askar G, Bayomi S (2013) Risk factors for autistic spectrum disorders at Assiut City. J Educ Pract 4(28):14757

25. Bentov Y, Kordysh E, Hershkovitz R, Belmaker I, Polyakov M, Bilenko N, Sarov $B$ (2006) Major congenital malformations and residential proximity to a regional industrial park including a national toxic waste site: an ecological study. Environ Health 5(1):1-9

26. Briggs D (2003) Environmental measurement and modelling: geographical information systems. Exposure assessment in occupational and environmental epidemiology 61. https://doi.org/10.1093/acprof:oso/97801 98528616.003.0004

27. Shore DL, Sandler DP, Davey FR, Mcintyre OR, Bloomfield CD (1993) Acuteleukemia and residential proximity to potential sources of environmentalpollutants. Arch Environ Health 48:414-420

28. Sarov B, Bentov Y, Kordysh E, Karakis I, Bolotin A, Hershkovitz R, Belmaker I (2008) Perinatal mortality and residential proximity to an industrial park. Arch Environ Occup Health 63(1):17-25. https://doi.org/10.3200/AEOH.63.1.1 7-25

29. Roberts AL, Lyall K, Hart JE, Laden F, Just AC, Bobb JF et al (2013) Perinatal air pollutant exposures and autism spectrum disorder in the children of nurses' health study II participants. Environ Health Perspect 121(8):978-984. https://doi.org/10.1289/ehp.1206187

30. Guinchat V, Thorsen P, Laurent C, Cans C, Bodeau N, Cohen D (2012) PrePeri- and neonatal risk factors for autism. Acta Obstet Gynecol Scand 91(3): 287-300

31. Salhia HO, Al-Nasser LA, Taher LS, Al-Khathaami AM, El-Metwally AA (2014) Systemic review of the epidemiology of autism in Arab Gulf countries. Neurosciences (Riyadh) 19(4):291-296

32. Kardas F, Bayram AK, Ozmen S, Özdemir Demirci E, Akin L, Canpolat M et al (2016) Increased serum phthalates (MEHP, DEHP) and bisphenol A concentrations in children with autism spectrum disorder: the role of endocrine disruptors in autism etiopathogenesis. J Child Neurol 31(5):629635. https://doi.org/10.1177/0883073815609150

33. Memari A, Ziaee V, Mirfazeli F, Kordi R (2012) Investigation of autism comorbidities and associations in a school-based community sample. Journal of Child and Adolescent Psychiatric Nursing 25(2):84-90

34. Gorrindo P, Williams KC, Lee EB, Walker LS, McGrew SG, Levitt P (2012) Gastrointestinal dysfunction in autism: parental report, clinical evaluation, and associated factors. Autism Res 5(2):102-108

35. Jahan A, Rezina-Parvin SZR, Bugum D (2014) Familial, social and environmental risk factors in autism: a case-control study. Bangladesh Med Res Counc Bull 40(3):113-117. https://doi.org/10.3329/bmrcb.v40i3.25233

36. Chonchaiya W, Nuntnarumit P, Pruksananonda C (2011) Comparison of television viewing between children with autism spectrum disorder and controls. Acta Paediatr 100(7):1033-1037. https://doi.org/10.1111/j.1651-222 7.2011.02166.x

37. De Cock M, Maas YG, Van de Bor M (2012) Does perinatal exposure to endocrine disruptors induce autism spectrum and attention deficit hyperactivity disorders? Review Acta Paediatrica 101(8):811-818. https://doi. org/10.1111/j.1651-2227.2012.02693.x

38. Walker CH, Krakowiak P, Baker A et al (2015) Preeclampsia, placental insufficiency, and autism spectrum disorder or developmental delay. JAMA Pediatr 169(2):154-162

39. Atladóttir HO, Pedersen MG, Thorsen P, Mortensen PB, Deleuran B, Eaton WW et al (2009) Association of family history of autoimmune diseases and autism spectrum disorders. Pediatrics 124(2):687-694

\section{Publisher's Note}

Springer Nature remains neutral with regard to jurisdictional claims in published maps and institutional affiliations.

\section{Submit your manuscript to a SpringerOpen ${ }^{\odot}$ journal and benefit from:}

- Convenient online submission

- Rigorous peer review

- Open access: articles freely available online

- High visibility within the field

- Retaining the copyright to your article

Submit your next manuscript at $\boldsymbol{\nabla}$ springeropen.com 